\section{The Beginning of My Study of the Turin Shroud}

The foflowing is an excerpt from a new book "Judgement Day for the Turin Shroud" by Walter McCrone now in press and due out by April 1 . In "Judgement Day for the Thrin Shroud," Dr. McCrone covers his work on $32-2^{\prime \prime} \times 5 / 8^{\prime \prime}$ sticky tapes that, applied to the Shroud in 1978 removed over 40,000 linen fibers, those in image areas are coated with sepia-colored substances absent on non-image area tapes. He contrasts his work and conclusions with those of members of STURP (Shroud of Turin Research Project) who believed, and still believe, the "Shroud" to be authentic. He also covers the efforts of the Church to make him see the errors of his ways and to recant. Finally, he relates how Father Rinaldi (who had spent years trying to "convert" him) decided to apologize for his stand and admit the "Shroud" is an artist's painting.

The following is a short section from this book with only minor changes or additions to present it as a single article. Ordering information may be found on page 8 of this publication. Orders received by March 30 will enjoy the $22 \%$ reduced pre-publication price or $33 \%$ reduced price for additional copies.

On Christmas day, 1978, I began to study the tapes in more detail, using polarized light microscopy. Following is a photocopy of page 13 of my Shroud research notebook. The preceding pages covered the sampling plan, a listing of the 32 tapes with locations on a photograph of the Shroud (Cover Image), and a record of the photographs of all 32 tapes.

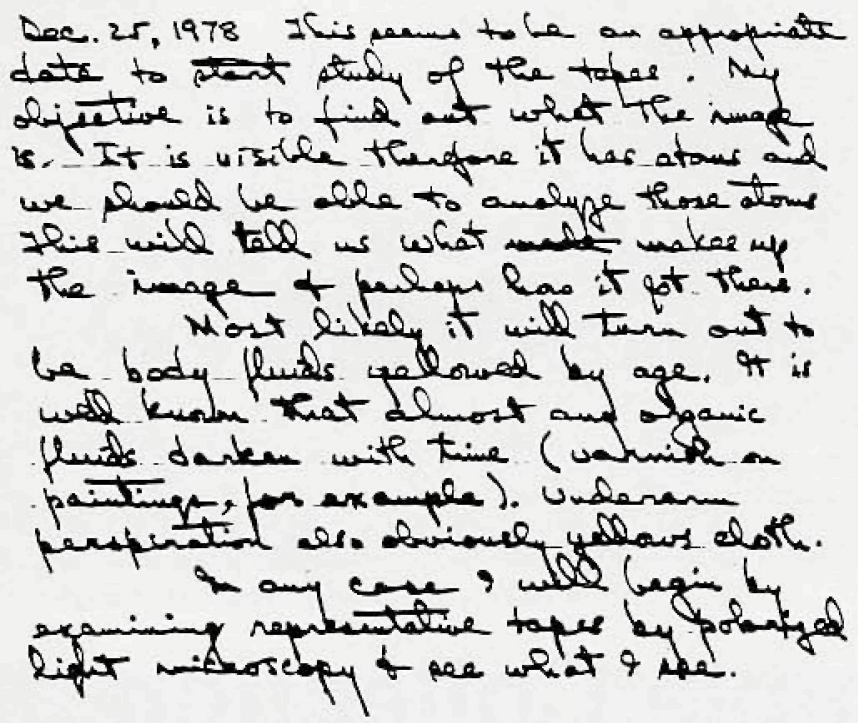

Before beginning a detailed study of tapes of the Shroud fibers, I studied a group of photomacrographs of the Shroud taken by STURP members, Sam Pellicori and Mark Evans, in Turin. Most showed image areas covered with red particles (Figure 1). My first look at the actual tapes microscopically began with tape 1-AB, a tape from the right foot. First, with transmitted light and then with reflected light. I noted that the red particles are the same color as the image color in Pellicori and Evan's photomacrographs. After looking at a few more tapes and finding more red particles, decided to concentrate on one sample.

Figure 2 shows several particle-coated linen fibers from tape $3-\mathrm{CB}$ with two large red-orange particle aggregates. One of the two is shown at a higher magnification (Figure 3). It appears to be a concentration of tiny orange-red particles in a transparent matrix-like pigment particles in a dried paint fragment

Figure 4 shows a typical higher magnification view of the red particles on blood-image tape $3-\mathrm{CB}$. This picture was taken through the tape backing. It shows a linen fiber with well-dispersed orange-red particles.

These particles are firmly attached to the fiber. This could indicate an adhesive (paint medium) layer. This is further indicated by the single-

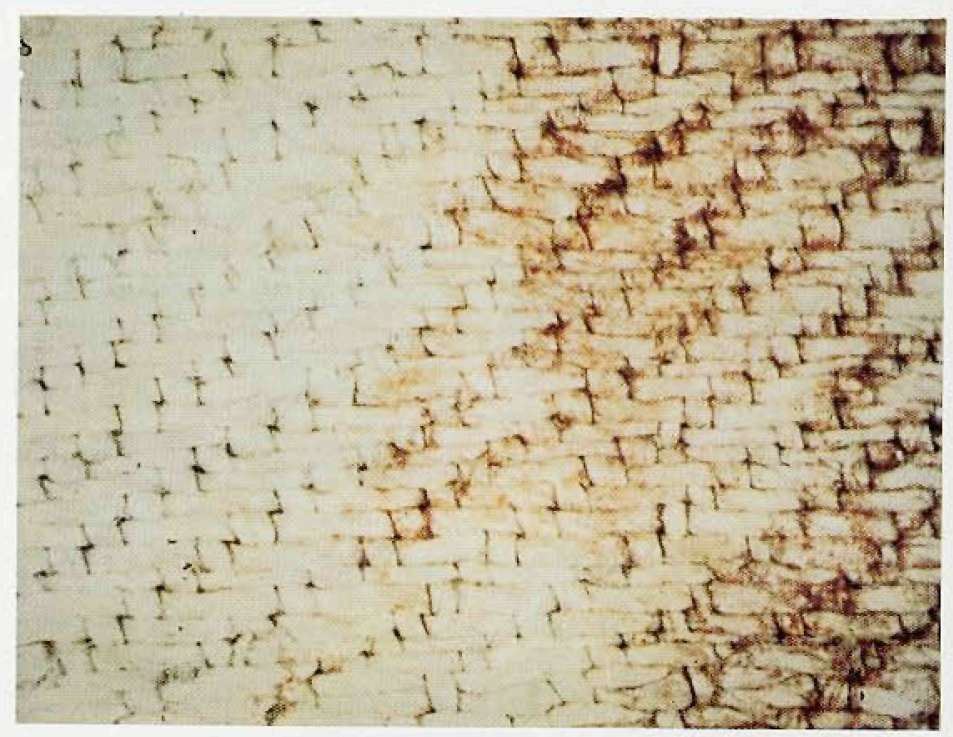

Figure 1: A Photomacrograph of a "blood-stain" (by Sam Pellicori), $16 \mathrm{X}$

particle dispersion of the pigment. This can only be done by applying a liquid with well-dispersed particles to the fiber where the volatile liquid evaporates leaving a dry film with the encapsulated particles.

Finally, on January 10, I took a higher magnification look (2500 times) at the red particles (Figure 5). Obviously, I was having trouble calling these particles a paint pigment. If I had seen the same red particles in a Raphael painting I would have immediately, and without question, called them red ochre and gone on to identify the other particles. It was difficult to overcome my conditioning that the Shroud would be authentic and the red image would be natural substances characteristic of a crucified Christ. By February 2, 1979 I was prepared to overcome my earlier conditioning

By March, I had compared these particles with actual (my) blood on a linen cloth (Figure 6)

I had also found so much iron oxide and so little other colored material on the image tapes, I was ready to say red ochre was the image pigment. The particles were isotropic hence not pure hematite but they matched red ochre in size, shape and color. This was a common red pigment in medieval times (and still today). It was called "sinopia" in the fourteenth century

Later in March (2th-27th), I attended a STURP meeting in Santa Barbara, their First Post-Data-Acquisition Conference. I spoke of finding large quantities of red ochre particles on the Shroud and on image tapes. I suggested they could be the Shroud image and that we should all be careful not to draw premature

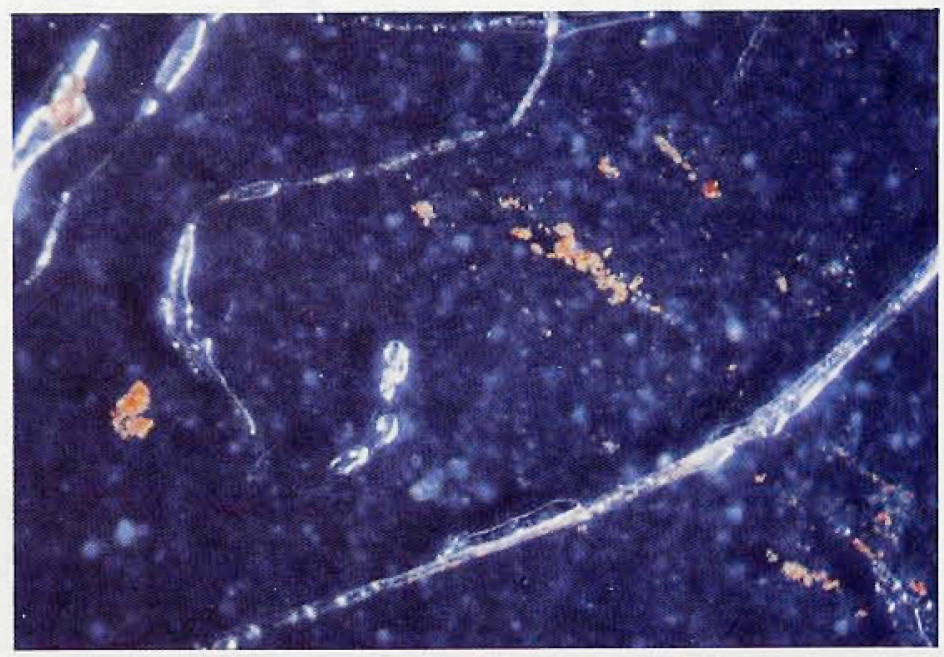

Figure 2: Several particle-coated linen fibers and pigment aggiomerates from tape 3-CB $100 \times$ 
conclusions with respect to authenticity. "If anyone says it is authentic, I may have to differ." I showed some slides of the red ochre on image area tapes but convinced no one. It was apparent that most, if not all, of the other attendees felt the Shroud was real. The large wooden crosses around the necks of some of the STURP officers was one disturbing indication.

I returned to Chicago to continue studying the tapes. Although nearly all of the colored particles on the tapes are red ochre, 1 did see other extraneous substances. But, if I could remove all of the red ochre from these tapes, there would be too little color remaining to form a visible image on the Shroud. The color of the particles, a reddish orange, matches very well the "sepia" color of the Shroud image. The ratio of the number of red ochre particles to the number of other extraneous colored particles is at least 1,000:1. Most of the red ochre particles are very tiny, less than 1 micrometer $(1 / 25,000$ inch) in diameter. Since the extraneous but rare particles may be of interest, I will list them: silk, wool, linen and cotton fibers of various colors, wax spatters, bird feather fibers, rodent hairs, mica, limestone (calcite), quartz, aragonite, starch grains (corn and wheat), pollen (average less than $2-3$ pollen grains per tape), mold spores, trichomes (leaf hairs), flyash (oil soot, power plant incinerator, trash burning), Jeweler's rouge, paper fibers, pigments (madder, orpiment, yellow ochre, azurite), paint fragments (titanium white, ultramarine, yellow ochre), plant and insect parts, charred linen fibers, etc. I couldn't help thinking of an artist's studio when I saw the pigments.

A visitor in my lab casually asked what I was looking at one day as I was

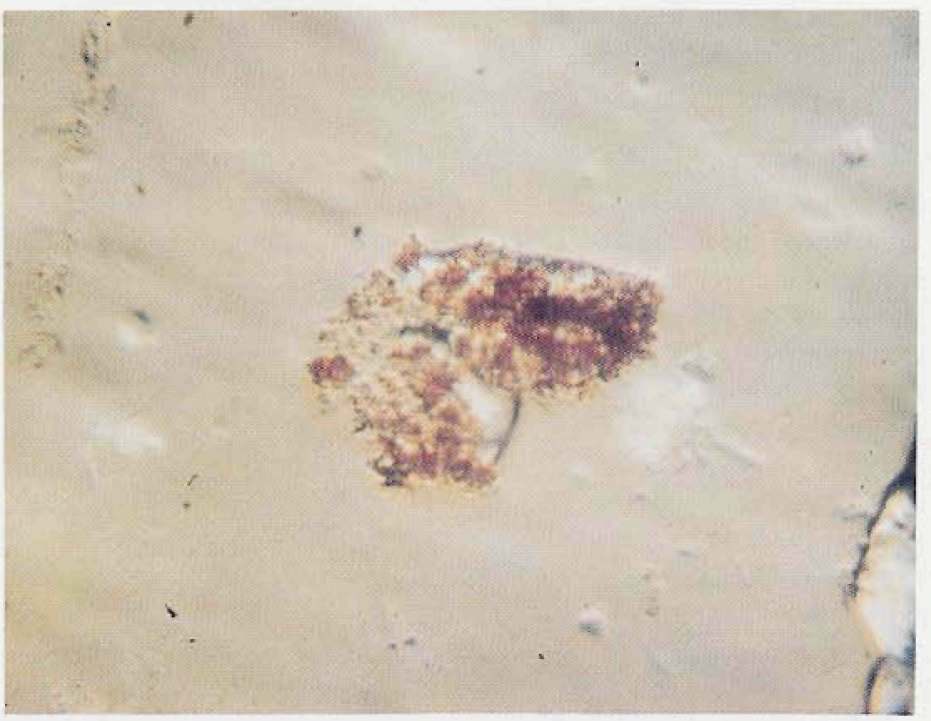

Figure 3: One of the pigment agglomerates (paint residue) enlarged, $400 \mathrm{X}$

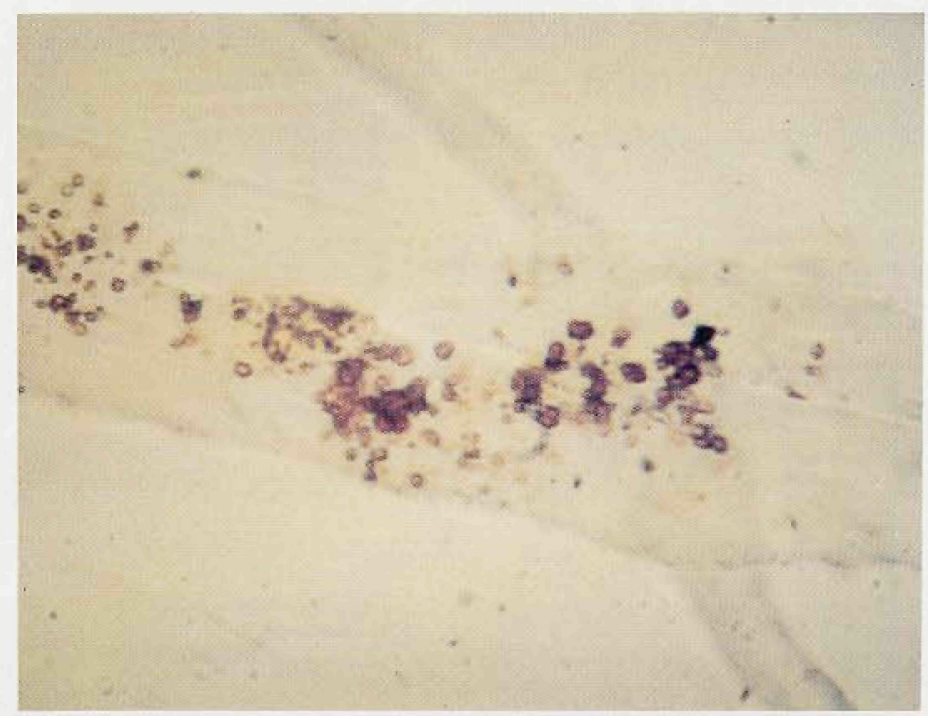

Figure 4: Typical red ochre pigment particles on a 3-CB fiber, $1000 \mathrm{X}$ looking for extraneous particles on the Shroud slides. I said, just as casually, that I was identifying particles in a dust sample. "What do you find?" says he. "Well, here I see several linen fibers. Here's a wool fiber and (as I move the slide) here's a limestone crystal and some fungal spores." "You mean," says he skeptically, "you just look at these things and you know what they are? You don't have to test them?" I said that sometimes I did have to "test" them but particles l'd seen dozens, if not hundreds of times before, I could recognize at sight - just as I recognized him when he came in or the way I instantaneously recognize thousands of large objects such as apples, pencils, dogs, the Eiffel Tower, Boeing 747 or Australia on a map of the world. Most small particles magnified several hundred times by a microscope are as distinctive as the thousands of larger objects we recognize every day without a microscope.

He left not knowing whether I was pulling his leg or not. I wasn't. In identifying cars, common flowers and birds or other objects, we don't have to "make tests." In a real sense, however, a microscopist is making tests when he "looks" at a particle. He notes particle shape that tells him it is or is not crystalline, has been precipitated, ground to reduce size, or weathered. $\mathrm{He}$ notes size (diameter, length, etc) telling him it is small like a pigment, or a distinctive size and shape of say, pollen, starches, natural fibers, etc. He sees a darkness or lightness of particle boundary that tells him the refractive index relative to its mountant and, by focusing, whether it is higher or lower in index.

- Continued on Page 16 -

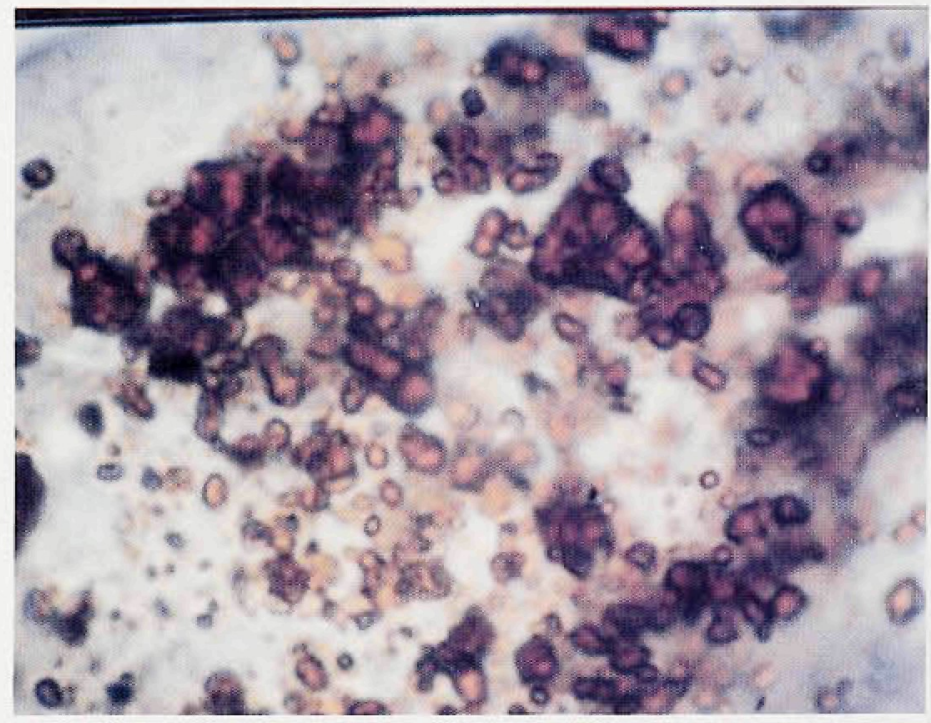

Figure 5: Another "blood-image" area with red ochre pigment particles, 2500X

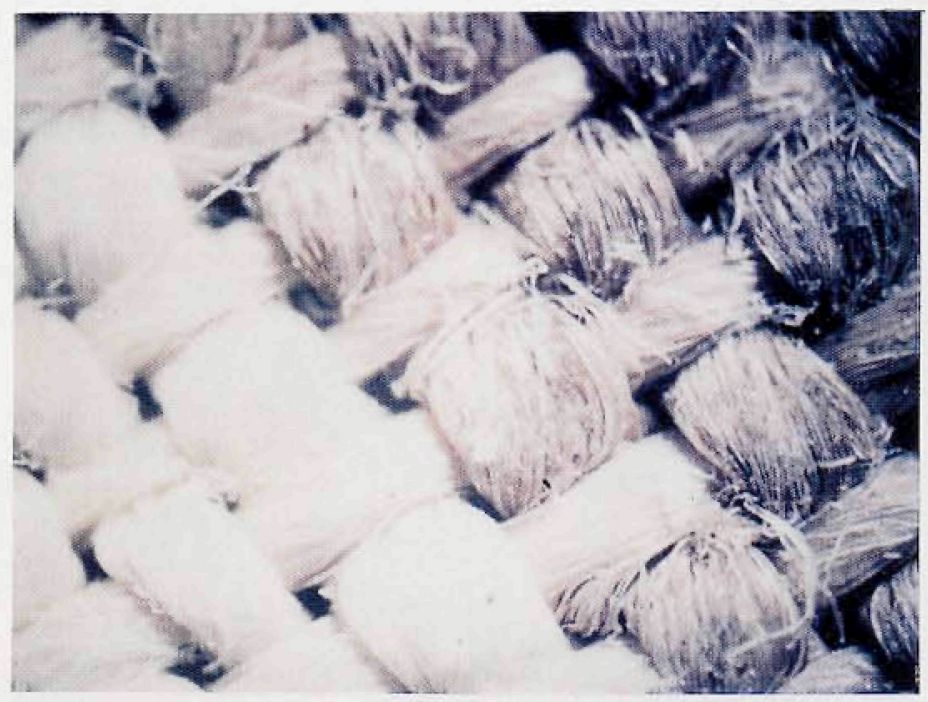

Figure 6: Real blood on a linen cloth, 50X 


\section{When Results Count...}

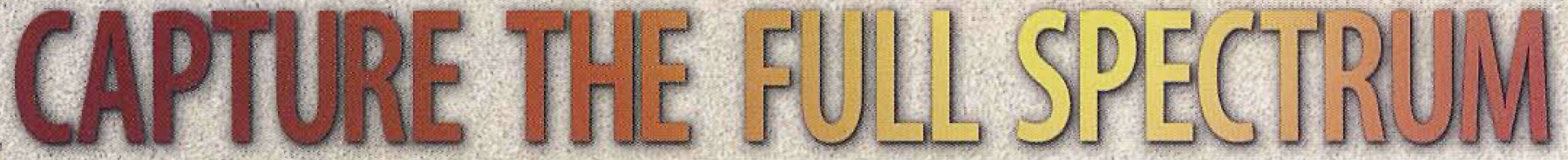

ULTRA-HIGH-RESOLUTION, element-specific acquisitions make our new IbeX WD

spectrometer the perfect complement to EDS applications. For full-spectrum WDS applications, we offer the APEX fully focusing WD spectrometer.

These sophisticated high-sensitivity instruments, along with our VOYAGER $x$-ray microanalysis and digital imaging system and our superior line of $x$-ray detectors, provide a complete solution for your applications.

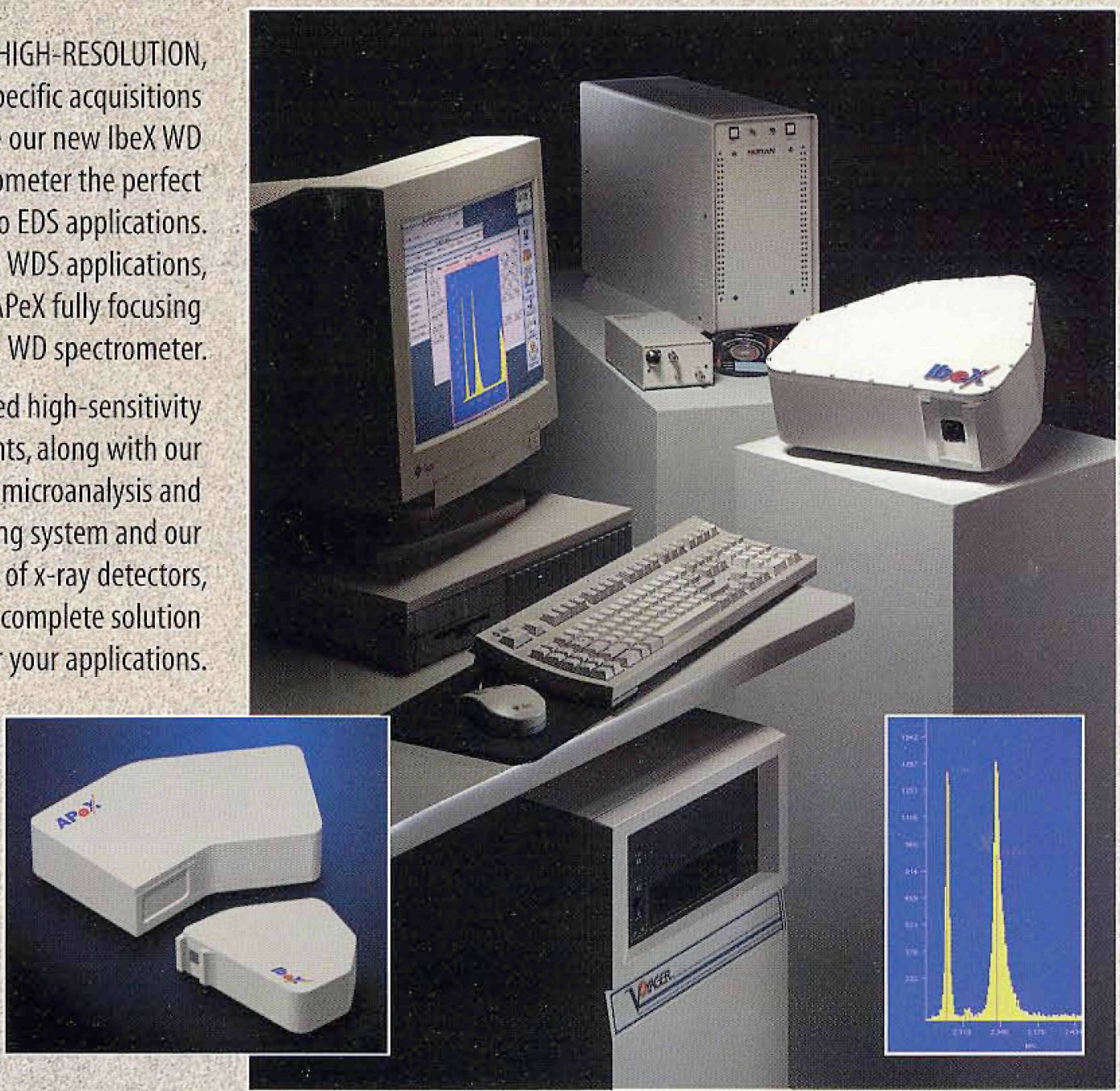

4.7.
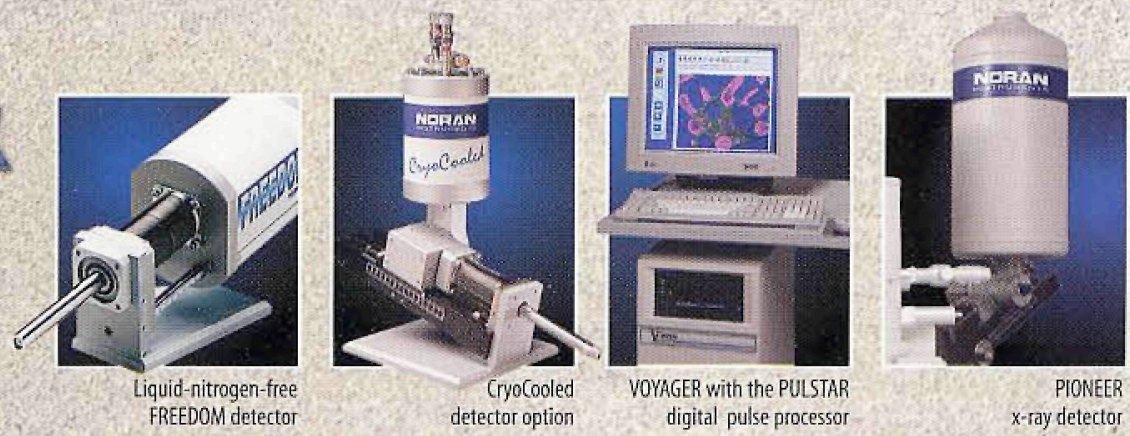

for details, visit our Web site or contact your NORAN Instruments sales representative.

Visit us at PITTCON

Booth 1241-1242

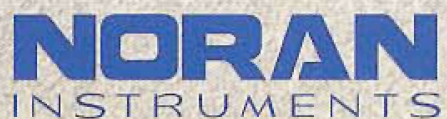

NORAN Instruments Inc., Corporate Headquarters 2551 West Beltline Highway, Middleton, WI 53562-2697 USA Tel.: 6088316511 , Fax: 6088367224

Internet: voyager info@noran.com World Wide Web: http://www.noran.com

NORAN Instruments B.V., Tel.: 3135 6998888, Fax: 31356949913

NORAN Instruments GmbH, Tel.: 49725197910 , Fax: 497251979111

NORAN Instruments Japan, Tel.: 8133298 8451, Fax: 81332988441

NORAN Instruments Korea, Tel.: 82342708 3091, Fax: 823427083093

NORAN Instruments U.K., Tel.: 441908696290 , Fax: 441908696292 